\title{
Visible absence, invisible presence

\author{
Feminist film history, \\ the database, and the archive
}

\author{
Eirik Frisvold Hanssen
}

In this essay I aim to address a series of theoretical and methodological questions relating to current projects that disseminate film historical research focusing on women's contributions, and in particular the role of the film archive in these efforts. Although the argument is of a general nature, it is nonetheless informed by specific circumstances. The essay was written in conjunction with the National Library of Norway's involvement in a specific project-the website, Nordic Women in Film, initiated by the Swedish Film Institute, and linked to the research project 'Women's Film History Network: Norden' (2016-2017). ${ }^{1}$ In a newspaper commentary on the launch of the Norwegian content published on Nordic Women in Film in December 2017, film scholar Johanne Kielland Servoll described the website as a kind of 'awareness project' (erkjennelsesprosjekt) similar to the logic of counting within discourses on gender equality or the Bechdel-Wallace test, revealing how many-or how few-women who have worked behind the camera in Norwegian film history. ${ }^{2}$ At time of writing, the website includes biographies and filmographies relating to 295 Norwegian women working in the film industry, along with 45 in-depth articles and interviews covering a variety of Norwegian angles on historical periods, professions, and film genres. 
Contributing material to be published on the website entailed a number of choices and questions for the National Library of Norway, some of which I will examine more thoroughly in what follows. What should be included in such a website? And how can the film archive in itself be activated in writing the history of women's roles in film, both in a practical and perhaps political sense?

When framing projects that attempt to display the role of women in the film industry, whether by grouping the historical and the contemporary, as in the Nordic Women in Film website, or having a delimited historical period, such as the database of the Women Film Pioneers Project, focusing exclusively on the silent era, ${ }^{3}$ one seems to have to grapple with two sets of co-existing binaries that are interrelated but also fundamentally different: what I would argue should be termed the invisibility-visibility binary on the one hand, and the absence-presence binary on the other.

The invisibility-visibility binary is concerned with how film history generally is written-who is mentioned, who is left out, and why. On the other hand, the absence-presence binary rather emphasizes how the film industry works, with the main attention usually (but not necessarily solely) directed towards the present, often focusing on absences, the lack of women in certain key functions. The notion of key functions in film production are central to both Norwegian and Swedish discussions and film policies on gender equality in film production, and usually refers to three professions: directors, screenwriters, and producers. In this model, some kinds of work, and some types of films, are inevitably considered more important than others.

So what do the words absence, presence, visibility, and invisibility mean in this context? According to the Oxford English Dictionary (OED), the word 'absence' can be defined as the 'state of being absent or away from a place, or from the company of a person or persons. ${ }^{4}$ The word is usually contrasted with 'presence', defined as 'the fact or condition of being present; the state of being with or in the same place as a person or thing; attendance, company, society, or association. ${ }^{5}$ Referring to these dictionary definitions, Amanda Bell points 
out that the two terms, absence and presence, are dependent upon 'the notion of being', which means occupying a place. Therefore, Bell argues, 'the definitions of presence and absence explicitly rely upon the states within which they are found', which can be defined as, for example, the world, images or representations. ${ }^{6}$ In our case, absence and presence can be located within both the film industry throughout history and in the writing and remembrance of that history. According to the OED, 'visibility' refers to the 'condition, state, or fact of being visible; visible character or quality; capacity of being seen (in general, or under special conditions)' and also the 'degree to which something impinges upon public awareness; prominence.7 'Invisibility', on the other hand, is the 'quality or condition of being invisible; incapacity of being seen. ${ }^{8}$ While absence is understood in contrast or opposition to presence, both visibility and invisibility are categories that presuppose presence. The issue is rather the capacity or incapacity of that which in fact is present to be seen, or to affect public awareness. But absences can and should also be made visible. One productive way to display absence is of course using statistics. The fact that zero per cent of Norwegian feature films between 1911 and 1948 were directed by a woman speaks volumes, but does not tell the whole story.

The notion of absence was central to early feminist film theory from the very first. Janet Bergstrom and Mary Ann Doane argued that the beginning of the theorization of the female spectator in feminist film theory took place in Laura Mulvey's seminal 'Visual Pleasure' essay in 1975, where ironically, 'its "origin" is constituted by an absence. ... What was so overwhelmingly recognizable in "Visual Pleasure" was our own absence." This notion of absence was, of course, followed by extensive academic work on female spectatorship, combining empirical historical research with feminist theoretical perspectives (by the likes of Miriam Hansen, Janet Staiger, and Jackie Stacey), and subsequently discourses on how to deal with other forms of 'absences' from these accounts, linked, for example, to ethnicity and sexuality.

If we assume that both absence and presence can be made both 
visible and invisible, are there ways to think of these two sets of binaries together, particularly in film historical research? How can one make visible the striking absence of women in certain key functions in the film industry at the same time as one similarly makes visible the significant, continual (often unseen or invisible) presence and contribution of women throughout film history? In short: how do we make absence and presence visible at the same time?

Regardless of emphasis, projects such as Nordic Women in Film and Women Film Pioneers entail explicit ambitions for change, directed towards an understanding of the past, as well as the future. One type of change is connected with how film history is written and understood; another type towards future film policies. Different forms of aims involving different forms of change also demand diverse methodologies, to a large extent informed by specific institutional conditions-bringing together the practices of film archiving, film historical research, and contemporary film policy.

Both film historiography and feminist film theory view the medium itself, individual works, or contexts and practices in the light of specific formative cultural and social structures. As a database, the Nordic Women in Film project is interesting in the way its formation, by the Swedish Film Institute, has been explicitly described as an effort to achieve a particular, predefined goal: gender equality in film production. The rationale for including a database of female film professionals throughout history in an effort to implement specific film policy strategies is explained by the assumed polemic function of such a website. As argued in a paper published by the Swedish Film Institute on the European Council website, efforts 'to achieve gender equality are often met by arguments and explanations as to why it simply isn't possible', and one strategy is 'to meet every argument with an action' and 'each challenge with a constructive suggestion. ${ }^{10}$ The first of these arguments is defined as follows: 'There are very few competent female filmmakers'. The statement itself is not attributed to anyone, but seems to be intended as a composite of contemporary views (implicit or explicit) without a clear source. At any rate, the Swedish Film Institute's response is: 
'No, we disagree. There are plenty of competent women making film. However, those women are not visible enough. This is why we are setting up a web site to make female filmmakers in the Nordic region visible, from the early days of cinematic art up to the present day. The concept of the website as a response to an argument, in order to subsequently reach particular goals, is repeated in an article by Johan Fröberg of the Swedish Film Institute, claiming that the website, 'by showing the plethora of successful Nordic women in film, will refute the argument that there are only a few competent women filmmakers. ${ }^{11}$

When the aim of the project was initially described on the website itself, in a short paragraph the two binaries of absence-presence and invisibility-visibility were posited together in a way that both demonstrates their interrelationship as well as seemingly irreconcilable differences. The role of women throughout film history was presented in the following manner:

In the early days of film there was a relatively high proportion of women working in the industry. They disappeared with the rise of the talkies-and did not reappear until the 1970s, even though there were pioneers and individuals active during most decades. Quite simply, it is time to showcase these women, to accord the stories and professional competencies of women in Swedish film history their rightful place, and to take a closer look at films and contributions that have been forgotten, neglected-or perhaps written off by male corps of critics. ${ }^{12}$

This is a story of a strong female presence in the silent film era, followed by a 'disappearance' at a particular point in history ('with the rise of the talkies') and a subsequent 'reappearance' in the 1970s. Even though the verbs 'disappear' and 'reappear' are used, there is also the assertion that women did not completely vanish-'there were pioneers and individuals active during most decades' (although the phrase 'most decades' actually implies a total disappearance at some point between the 1930 and 1960s). Perhaps 
more importantly, the website itself in effect negates the assumption of a disappearance, by containing biographies of approximately 775 Swedish female film professionals through the entirety of Swedish film history, and thus an inclusive approach to cinematic authorship, along with in-depth articles on female film exhibitors and cinema musicians. And along with the account of the fluctuating absence and presence of women, there is also an argument concerning visibility and invisibility, the need to 'showcase', to accord certain contributions 'their rightful place' in the writing of Swedish film history, as well as descriptions of (gendered) dynamics of power excluding, neglecting, and undervaluing certain contributions.

Several film scholars, including Jane Gaines, Vivian Sobchack, and Vicki Callahan, have pointed out that feminist film historiography always relates to the present-as Gaines has put it, 'the "historical turn" in film feminism is also, and as much about feminist film theory. ${ }^{13}$ The way the formation of the Nordic Women database was prompted by contemporary film policy goals somehow echoes Callahan's call for a non-chronological media-archaeological approach to film history, conceived within the framework of the present. ${ }^{14}$ There is nonetheless always a danger of aligning historical research with overly specific, predefined, instrumental goals-to know a little too well in advance what one is looking for. Historyand archival research-should ideally provide the possibility of surprise. To what extent are models for writing and presenting the history of silent film applicable for the writing and display of comparable histories about later periods, and the understanding of the current situation? To change the way the history of film is written must also involve the rethinking of categories. What does 'participation' and 'inclusion' in the film industry mean? What does 'absence' and 'exclusion' refer to? How broad should the notion of 'authorship', or even 'key function', be?

In an essay on the work ahead for what she characterizes as 'feminist media historiography', Shelley Stamp refers to her own research on the filmmaker Lois Weber, and reflects on the discrepancy between the extent of Weber's achievements and the invisibility 
of these achievements both in contemporary discourses and the subsequent writing of film history. Similarly, Stamp argues that there is a discrepancy between the wide range of existing scholarship on women's engagement with early film culture produced in the past two decades and the limited impact this work has had on dominant accounts of silent film history, both in popular and scholarly domains. Feminist historiography is not a 'competing narrative that repeats the methods and tropes of conventional history'. Stamp encourages film historians to look 'past the screen', to produce 'film scholarship without film', focusing on women's part in shaping discourses on cinema, in roles such as film critics and film censors. ${ }^{15}$ Stamp also argues that one important strategy for achieving a rewriting of film history is to 'fundamentally reconceive authorship', because the 'true scope of women's engagement with, participation in, and production of early movie culture comes into view only when we move beyond a focus on female directors and screenwriters' - not least because women's contributions might be obscured or uncredited. To write feminist media history should also entail tracing 'alternative genealogies' and studying 'alternative archives and unorthodox materials' not usually studied in traditional film history. And importantly, Stamp argues that a feminist media history 'must make absence productive'. Absences do not necessarily need to be filled, but could rather be made visible, as in Giuliana Bruno's work on Elvira Notari, where the impossibility of reconstructing a full picture is acknowledged by making absences evident, which in Bruno's account is comparable to the preservation of frescoes.

The online database, The Women Film Pioneers Project, launched by Columbia University in 2013, focuses on female film professionals in the silent era. The front page of the website presents 'the inclusion of producers, directors, co-directors, scenario writers, scenario editors, camera operators, title writers, editors, costume designers, exhibitors, and more' as a means to 'make the point that they were not just actresses. ${ }^{16}$ Unlike the Nordic website, several actresses are included but the main focus is given to women working behind the 
scenes in a broad sense. Like the Nordic website, the Film Pioneers database is also associated with a set of goals, albeit articulated quite differently. The goal of the project is 'to jumpstart historical research on the work of women filmmakers from the early years of cinema, ending with the coming of sound; to facilitate a crossnational connection between researchers, to reconfigure world film knowledge by foregrounding an undocumented phenomenon: these women worked in many capacities'. The Pioneers website also foregrounds the numerous female film professionals in the silent era, claiming that more women 'worked at all levels inside and outside the Hollywood film industry in the first two decades than at any time since, and that the high incidence of women workers 'was not limited to the US'.

Reclaiming the word 'pioneer', associated with traditional male-dominated film historiography, a striking aspect of the database is the wealth of occupations that are included. An important experience in the project, again according to the website, was that researchers 'found more women than anyone expected to find', leading to the adoption of the maxim that 'What we assume never existed is what we invariably find'. This is both reflected in thematic articles on female film editors, camera operators, film colourists, film exhibitors, and the presence of African-American women in the film industry, as well as in the more than one hundred types of professions (some overlapping) associated with women listed in the database. The wealth of occupations, and subsequently a broad notion of cinematic authorship suggest the potential for tracing important continuities with regard to women's contributions to film history, also in periods that seem to be primarily associated with notions of disappearance, absence, and exclusion. The Scandinavian entries, though limited in number, reflect the inclusive approach, and include the Norwegian film censor, journalist and theatre critic, Fernanda Nissen, Swedish film censor, Marie Louise Gagner, and Swedish title writer and designer, Alva Lundin. ${ }^{17}$

Victoria Duckett and Susan Potter have argued that the field of research on women and silent cinema provides 'the opportunity to 
explore film history anew'. What distinguishes the period is how 'women are located at every stage and in all facets of the silent era filmmaking process'; it is precisely the recognition of a multitude of contributions, various forms of cinematic 'authorship' that they argue 'permits the critical expansion of the word "filmmaker" and its relation to histories of cinema, gender and modernity. ${ }^{18}$ So while research on women in silent film examines a period where women, according to many of the historians of the era, were involved in the film industry to a seemingly unequalled extent, the inclusiveness with regard to a multitude of professional contributions and forms of cinematic authorship could also constitute a useful foundation for the study of later periods, tracing the continuities in women's contributions throughout film history.

This is because, as Duckett and Potter point out, research reframing the significance of gender in early cinema involves a 'reorientation' not only of 'history but the approach and methodologies by which it is undertaken. ${ }^{19}$ Such a reorientation begins with the 'presumption that film history is incomplete', and here the authors in part direct their attention to the archive, in many ways the basis for the writing of history, and the way women's contributions are absent. The challenge lies in recovering the work of female filmmakers, in the broadest sense of the term, without replicating the implicitly masculinist paradigms of film theories and histories that excluded them in the first place.' As argued by Gaines, these contributions, not to mention the influence and power of women during this period, have not only been largely absent from traditional film historiography, but were also largely unacknowledged by feminist film theory in the 1970 onwards. ${ }^{20}$

A project such as Nordic Women in Film thus presents the opportunity both to activate and to reconsider the holdings of the archive. An archive is of course always comprised of very limited fragments and traces of the past, and could never assume to present history as a whole. Both the holdings of the archive, as well as access to these holdings, are the result of choices, which again are fundamentally informed by the relationship between knowledge and power. As 
Jacques Derrida argued, there is no political power without control of the archive, if not memory. Effective democratization can always be measured by this essential criterion: the participation in and access to the archive, its constitution, and its interpretation.' ${ }^{21}$ Consequently, what is missing from the archive is of course less likely to become part of scholarly research on film history. Thus, it becomes vital to ask how a foregrounding of the archive, of the collections, of the mechanisms that inform our holdings (many of them beyond our control-but certainly not all) and the glaring absence of certain materials in itself can contribute to an understanding of mechanisms of absence and exclusion in film history in a general sense. To include the archive-ourselves-as an agent of power actively taking part in processes of ignoring and forgetting might even spur us to seek out new collections, such as female film professionals' personal archives. Duckett and Potter argue for the identification of gaps in current film histories, linked to a notion of forgetting, implying that asking 'why' there is an absence is as important as asking 'who' is in fact absent. Another key question posed by the authors is difficult to resolve, but remains fundamental to the construction of a database on female authorship in cinema: 'How can we write histories of cinema that are more inclusive while not eliding processes of exclusion or other dynamics of power?'22 For an archive, one obvious strategy is self-reflection-drawing attention to the processes and dynamics involved in the archive itself, including, but not limited to selection processes (what material is included, accepted, or actively sought after), as well as other archival activities such as preservation and restoration (what materials are prioritized), the organizing of particular collections, including cataloguing and the production of metadata (to what extent is the existence of the material made known), and of course access for researchers and the general public.

In Vicki Callahan's edited volume on feminism and film history, symptomatically titled Reclaiming the Archive, she argues that 'the history we present as feminists always implies a kind of reclaiming, rewriting and recontextualization of materials', adding: 'What the 
cinema and feminism represents historically are new ways of seeing and thinking about the world, and as such the cinematic metaphor is a central one, I would argue to a feminist agenda. ${ }^{23}$ One of the sections in the book is titled 'Rewriting Authorship, ${ }^{24}$ suggesting new and more heterogeneous ways to see and think about cinematic authorship, which Callahan links to the broader film theoretical concept of 'enunciation', claiming that 'the attention for much feminist scholarship has been on finding alternative paths of entry into the codes of cinematic enunciation. Women's "voices" are then found in stars, audiences and formalist strategies rather than in the individual humanist author so prominent in most directorial studies. ${ }^{25}$ Although one can argue that these alternative paths have been mapped out by necessity, because of women's limited access to certain dominant arenas in the film industry, they have also been instrumental in broader film historical and theoretical debates, for example the importance of reception and exhibition contexts, and the critique of auteurist perspectives. As Yvonne Tasker argues in the same volume, 'the work of feminist film historians in documenting the contribution of women in the film industry represents not only an important attempt to write women's history but a rejection of the claims made by, or more typically on behalf of, one person-the male director to have priority over the text. ${ }^{26}$ At the same time, in part because the centrality of the filmmaker remains so strong in film discourse, Tasker also argues that the 'visibility of women filmmakers' (in a male-dominated field) is a crucial question that needs to be addressed.

Here, the challenges of limiting oneself to the absence-presence binary and a list of 'key functions' and a set definition of 'authorship' are pertinent, at least without a consideration of the historical and ideological reasons why certain credits are considered more valuable than others, including the recognition that the status of professional functions (for example, reflected in wages) fluctuate throughout history and across geographies and industries. To compare the current situation with a preceding period in film history, such as the silent era, the fact that women probably were more prominent 
in film production and film culture overall is not the only revelation. There are also numerous differences in standards, conventions, stylistic preferences and notions of authorship, across time as well as geographies. The prominent position of the set designer in European (perhaps especially German) film industries in the 1920s, in terms of prominence in the creative process, a status comparable to the director and screenwriter, the determining role for the look of the film, as well as billing and salaries, is well known, and can be contrasted with both the contemporary US film industry and the current situation in European cinema. ${ }^{27}$

In conclusion, I would like to include a brief example of how the archive itself, or perhaps rather the work carried out in the archive, can contribute to alternative discourses and ways of thinking about a national film history, and how individuals' contributions are counted. The Norwegian set designer, or 'film architect', Grethe Hejer (born 1926) donated her personal archive to the National Library of Norway in 2014. ${ }^{28}$ A trained architect, Hejer documented her work as a production designer over a career spanning four decades, which included 23 Norwegian feature films and 58 television productions. ${ }^{29}$ In addition to being a document of an astounding career, the archive obviously also provides extensive insight into Norwegian film and television production history in general. The archive also directed our attention to Hejer's career as a filmmaker, directing, or co-directing ten short films between 1974 and 1989, many in collaboration with film director Kåre Bergstrøm and writer André Bjerke, whom she also collaborated with on several feature films. Most of these films were shown on Norwegian television, but several were also screened at international film festivals. To acknowledge Hejer's practice as a filmmaker along with her work as a production designer, and for the first time producing a complete filmography, cannot in itself be characterized in terms of an 'archival find', meaning that it reveals something new or completely unknown-but thanks to research in connection with the archive, attention was drawn to notable and thoroughly overlooked film-making efforts. The example of 
Grethe Hejer demonstrates the necessity of looking in unexpected places, and the benefits of being open to including various forms of authorship (acknowledging the centrality of professions such as the production designer) and types of films (including short films, documentaries, and television productions). Our approach to the writing of film history should be informed by openness to what a 'key function', or significant contribution, entails, while also acknowledging the importance of increasing the visibility of the women who have succeeded in the male dominated arenas of film directing, producing, and screenwriting.

\section{Notes}

1 http://www.nordicwomeninfilm.com/ For the Nordic Women in Film project, see Jannike Åhlund's foreword and Ingrid Stigsdotter's introduction to the present volume.

2 Kielland Servoll 2017, 28-9.

3 Gaines et al. 2013.

4 OED s.v. 'absence'.

5 OED s.v. 'presence'.

6 Bell, 'absence/presence', Chicago School of Media Theory: Keywords, University of Chicago, https://lucian.uchicago.edu/blogs/mediatheory/keywords/ absence-presence/, accessed 16 June 2019.

7 OED s.v. 'visibility'.

8 OED s.v. 'invisibility'.

9 Mulvey 1975, 6-18; Bergstrom \& Doane 1989, 7.

10 Swedish Film Institute 2013.

11 Fröberg 2014, 26.

12 http://www.nordicwomeninfilm.com/about/. Editor's note: the quotation is from the version of the website that was launched in April 2016, and the 'About' page has since been updated.

13 Gaines 2004, 115-17; Sobchack 2006, 67; Callahan 2010, 2-3.

14 Callahan 2010, 2.

15 Stamp 2015.

16 Gaines et al. 2013, added emphasis.

17 Myrstad 2016; Olsson 2014; Bull 2014.

18 Duckett \& Potter 2015.

19 Ibid.

20 Gaines 2004, 113-14.

21 Derrida 1995, 4 n. 1. 
22 Duckett \& Potter 2015.

23 Callahan 2010, 5.

24 Ibid. 127-57.

25 Ibid. 127.

26 Tasker, 'Vision and Visibility: Women Filmmakers, Contemporary Authorship, and Feminist Film Studies' in Callahan 2010, 213.

27 See Bergfelder et al. 2007, 42-3; Thompson 2005, 53-7.

28 The description of Hejer's archive owes much to Øivind Hanche (2017) and Kirsti Ladegård (2018) and their work organising the archive, and Ladegård 2014 for an unpublished report on Hejer and her archive.

29 Including notable films such as De dødes tjern (Kåre Bergstrøm, 1958), Edvard Munch (Peter Watkins, 1974), and Hud (Vibeke Løkkeberg, 1986), and ambitious, high-budget television series such as Benoni og Rosa (Per Bronken, 1975) and Jenny (Per Bronken, 1982).

\section{References}

Bell, Amanda, 'absence/presence', Chicago School of Media Theory: Keywords, University of Chicago, https://lucian.uchicago.edu/blogs/mediatheory/keywords/ absence-presence/, accessed 16 June 2019. Bergfelder, Tim, Sue Harris \& Sarah Street, Film Architecture and the Transnational Imagination: Set Design in 1930 s European Cinema (Amsterdam: AUP, 2007).

Bergstrom, Janet \& Mary Ann Doane, 'The Female Spectator: Contexts and Directions', Camera Obscura 20-21 (1989): 5-27.

Bull, Sofia, 'Alva Lundin', in Jane Gaines, Radha Vatsal, and Monica Dall'Asta, (eds.)

Women Film Pioneers Project. (New York, NY: Columbia University Libraries, 2014) <https://doi.org/10.7916/d8-326g-2n79>

Callahan, Vicki (ed.), Reclaiming the Archive: Feminism and Film History (Detroit: Wayne State University Press, 2010).

Derrida, Jacques, Archive Fever: A Freudian Impression, tr. Eric Prenowitz (Chicago: University of Chicago Press, 1995).

Duckett, Victoria \& Susan Potter, 'Introduction: Women and the Silent Screen', Screening the Past 40 (special issue 'Women and the Silent Screen'), 2015, http:// www.screeningthepast.com/2015/08/introduction-women-and-the-silent-screen/.

Fröberg, Johan, 'Gender Equality in Swedish Films', in Maria Edström \& Ragnhild Mølster (eds), Making Change: Nordic Examples of Working Towards Gender Equality in the Media (Gothenburg: Nordicom, 2014).

Gaines, Jane, 'Film History and the Two Presents of Feminist Film Theory', Cinema Journal 44/1 (2004): 113-19.

- - Radha Vatsal \& Monica Dall'Asta (eds), Women Film Pioneers Project (Center for Digital Research \& Scholarship; New York: Columbia University Libraries, 2013-), https://wfpp.cdrs.columbia.edu/. 
Hanche, Øivind, 'Grethe Hejer', Nordic Women in Film, 2017, http://www.nordicwomeninfilm.com/person/grethe-hejer/.

Ladegård, Kirsti, 'Privatarkivet etter filmarkitekt Grethe Hejer, en presentasjon' (National Library of Norway, 2014).

- - 'I arkivet: filmarkitekt og scenograf Grethe Hejer', Nordic Women in Film, 2018, http://www.nordicwomeninfilm.com/i-arkivet-filmarkitekt-og-scenografgrethe-hejer/.

Myrstad, Anne Marit, 'Fernanda Nissen', in Jane Gaines, Radha Vatsal, and Monica Dall'Asta, (eds.) Women Film Pioneers Project. (New York, NY: Columbia University Libraries, 2016) <https://doi.org/10.7916/d8-arf4-0a52>

Mulvey, Laura, 'Visual Pleasure and Narrative Cinema', Screen 16/3 (1975): 6-18. OED, Oxford University Press, 2019, available at www.oed.com, accessed 16 June 2019. Olsson, Jan, 'Marie Louise Gagner', in Jane Gaines, Radha Vatsal, and Monica Dall'Asta, (eds.) Women Film Pioneers Project. (New York, NY: Columbia University Libraries, 2014) <https://doi.org/10.7916/d8-c89w-7y64>

Servoll, Johanne Kielland, 'De glemte kvinnene i norsk filmhistorie', Dagbladet 8 December 2017: 28-9.

Sobchack, Vivian, “Presentifying” Film and Media Feminism, Camera Obscura 21/1 (2006): 65-8.

Stamp, Shelley, 'Feminist Media Historiography and the Work Ahead', Screening the Past 40 (2015), http://www.screeningthepast.com/2015/o8/feminist-media-historiography-and-the-work-ahead/.

Swedish Film Institute, 'Towards Gender Equality in Film Production' (2013), available from https://www.filminstitutet.se/

Thompson, Kristin, Herr Lubitsch Goes to Hollywood: German and American Film After World War I (Amsterdam: AUP, 2005). 